\title{
Cybersecurity of the Unmanned Aircraft System (UAS)
}

\author{
Mariusz Pyzynski ${ }^{1} \cdot$ Tomasz Balcerzak $^{1}$ (D) \\ Received: 17 January 2021 / Accepted: 15 April 2021 / Published online: 17 May 2021 \\ (C) The Author(s) 2021
}

\begin{abstract}
In recent years, UASs have become more and more popular. There are many reasons for this; one of the most popular is the enhancement of drones' functionalities and improvement in battery life, stabilization, navigation, sensor technology, and much more. Many benefits drive growth. However, as the number of drones is expanding and their technological functionalities are evolving, drones' use brings many concerns and challenges that should not be underestimated. This refers to issues in the area of cybersecurity, privacy, and public safety. UASs, under the international, regional, and national regime of aviation law, are considered aircraft. Since there is no existing cybersecurity framework specific to the UASs, the civil aviation cybersecurity framework should apply to their operations. This paper will focus on the potential cyber threats against UASs, providing examples of cyber-attacks from the past. Further, the aviation cybersecurity framework's overview will follow to determine the current status of maturity at the international, regional (the European Union), and national (the Republic of Poland) levels. The paper's conclusion will address the proposed recommendations for the UAS and aviation industries to be considered and potential solutions in terms of applying the aviation cybersecurity framework into the operation of UASs.
\end{abstract}

Keywords UAS · Drones · Cybersecurity · Cyberspace

\section{Introduction}

The popularity and availability of the Unmanned Aircraft System (UAS), commonly known as drones, are emerging worldwide than ever before, which is caused by many different reasons related to the UAS operations as well as its functionality and potential usage across many sectors. The enhancement of design, functions, and advancements like longer battery life, better technology, navigation, etc. are the most common reason for the growing desire and exploitation of the UAS [1]. Generally, according to the report provided by PwC, the UAS are used in the following industries:

The version of the submitted paper appeared in the Proceedings of the 2020 International Conference on Unmanned Aircraft Systems (ICUAS'20), Athens, Greece.

Tomasz Balcerzak

tomasz.balcerzak@lazarski.pl

Mariusz Pyzynski

mariusz.pyzynski@gmail.com

1 Faculty of Law and Administration of Air and Space Law, Lazarski University, Warsaw, Poland agriculture, energy, utilities, security, entertainment, media, infrastructure, insurance, telecom, transport, and logistics [2]. The new drones, which are becoming more digitalized and connected, can be used for many purposes. Moreover, UASs are low-priced and readily available, which makes them beneficial for professional and recreational use.

The Federal Aviation Administration (FAA), in one of the reports, forecasted that in the United States by 2023 there will be a growth of $300 \%$ in the number of registered UAS [3]. Although the number of drones is constantly growing worldwide and more sectors find the UAS useful for their business operations, the digitalization and a high number of systems integrated into the UAS may bring some concerns and challenges (privacy, cybersecurity, public safety, etc.), not only for the operators but the entire industry.

Usually, the drones are being operated through software, using different portable devices, like smartphones, tablets, or laptops [4]. Thus, the UAS may be the subject of a cyberattack conducted by malicious actors having many different motivations (threaten the society, endanger public safety, financial gains, reputational damage, recognition, and much more) [5]. This brings also concerns for example in terms of safe UAS integration into the airspace and to what extent there is a cyber risk associated with that process. However, the UAS industry represents a high level of innovation and technology, 
there are still not enough regulations, standards, recommendations, and guidance materials that would address cybersecurity in this sector. Many questions and concerns remain without clear answers related to the safe and efficient process of UAS integration into the airspace. The most crucial challenge that should be addressed in this matter is cybersecurity. Integration of new systems and the UAS into the airspace may bring a lot of cybersecurity challenges that should be not be underestimated and addressed on time [6].

The FAA defines the UAS as an "unmanned aircraft and associated elements (including communication links and the components that control the unmanned aircraft) that are required for the pilot in command to operate safely and efficiently in the national airspace system" [7]. Moreover, the ICAO defines the unmanned aircraft as an "aircraft which is intended to operate with no pilot on board" and the unmanned aircraft system as an aircraft and all associated elements being operated without pilot present onboard [8]. Therefore, it should be noted here that the UAS, under the international regime of air law is considered as aircraft [9]. All unmanned aircraft, whether piloted remotely, fully autonomous, or even those using a combination of both, are subject to the Convention on International Civil Aviation (the Chicago Convention). Article 8 of Chicago Conventions articulates that "no aircraft capable of being flown without a pilot shall be flown without a pilot over the territory of a contracting State without special authorization by that State and in accordance with the terms of such authorization. Each contracting State undertakes to insure that the flight of such aircraft without a pilot in regions open to civil aircraft shall be so controlled as to obviate danger to civil aircraft" [10]. Therefore, based on the international regime of air law and its interpretative study, it should be stated that some provisions of the aviation cybersecurity framework (regulations, standards, recommended practices, guidance materials, etc.) should apply to the UAS and possibly questions and concerns that still have not received the answers, could be addressed over there.

This paper aims to analyze the concerns related to UAS cybersecurity and potential threats that can be caused by UAS operations. In order to better understand the potential threats, some analysis of the cyber-attacked that were carried out with the usage of drones will follow. Further, since it was stated that some provisions of the aviation cybersecurity framework might apply to the UAS operations, general overview of the current activities in this sector as well as the maturity of the framework at international, regional (the European Union), and national (the Republic of Poland) will be discussed. Based on this, the paper will provide some recommendations for the UAS and aviation industry of potential actions to better address the cybersecurity challenges.

\section{Deliberations on the Potential Cyber Threats against the UAS}

The term cyberspace was coined and popularized as early as 1984 by William Gibson, author of the cult cyberpunk novel Neuromancer. In his literary vision, he defined cyberspace as (...) a consensual hallucination experienced every day by billions of authorized users in all countries, by children taught mathematical concepts (...). Graphical representation of data from banks of all computers in the world. Unimaginable complexity (...) [11].

In the literature on the subject, cyberspace is defined as the totality of virtual connections ("non-spatial" in the physical, non-material sense) created and existing thanks to their physical manifestations (computers, telecommunications infrastructure) [12].

Generally speaking, it can be said that cyberspace is (...) the entirety of connections of human activity with the participation of ICT (Information and Communication Technology). In other words, (...) cyberspace is a network connecting computer systems including central units and their software, but also data, methods, and means of their transmission. Cyberspace includes Internet connection systems, ICT services, and systems ensuring the proper functioning of the country, i.e., transport and communication systems, energy, water and gas infrastructure systems, and health care [13].

For example, in the Republic of Poland, cyberspace has been defined by law as the space for processing and exchanging information, created by ICT systems (teams of IT devices and software cooperating with each other) ensuring processing and storage, as well as sending and receiving data via telecommunications networks [14].

Cyberspace as a sphere of human activity is fundamentally different from physical space. First of all, it is necessary to indicate independence from the place occupied in physical space (in the geographical sense). The only requirement is that it is technically possible to join the network. Moreover, individual devices connected to the network at a given moment have quick and equal access to other elements of the system, similarly to other participants with the same status. Secondly, it is necessary to point out the decreasing cost of entering the network and taking various actions in it. The knowledge and skills necessary to undertake such activities are also diminishing due to the apparent tendency to simplify the interface as much as possible. Third, the network largely allows the participant to remain anonymous. The traces that the user leaves behind on the network are actually the traces of the computer they are using. A separate problem is the association of this computer with a specific human. There is also the possibility of full anonymization [15]. 
Cyberspace has become - as defined in the US National Strategy to Secure Cyberspace - the "nervous system of the state": (...) our economy and national security have become fully dependent on technology and IT infrastructure. The functioning of the critical infrastructure depends on the efficiency and security of cyberspace [16].

The importance of cyberspace for the modern state and society makes the problem of its security more and more important.

As Bogusław Pacek and Romuald Hoffman state, (...) cyberspace security (...) can be defined as no risk of losing information data in cyberspace (...) It is clear that the resource we protect is information [17].

The cited authors clearly situate the issue of cyberspace security in terms of information warfare and war, which makes it necessary to adopt as a starting point for further considerations of state information security as an integral part of national security, and then information threats.

As part of such an approach, many determinants of information security should be taken into account, and above all the fact that:

- information is a strategic resource of the state,

- information and the resulting knowledge and information technologies become the basic production factor,

- the broadly understood information sector generates a significant part of the national income,

- decision-making processes in other sectors of the economy and social life are largely dependent on the processing and transmission systems information,

- disruption of the correct operation of information and control systems does not require high material expenditure,

- competition between opponents will transfer to the level of information warfare,

- information technologies have become an important element of the functioning of state security, including the armed forces, for example, by conducting disinformation.

Eugeniusz Nowak and Maciej Nowak propose a very broad definition of information security, according to which it is the state of internal and external conditions that allow the state to have, survive and freely develop an information society. According to the authors, this state is achieved when the following conditions are met:

- strategic state resources are not at risk,

- authorities make decisions based on reliable, relevant, accurate, and up-to-date information,

- the flow of information between state authorities is uninterrupted,

- the functioning of the ICT networks that make up the state's critical ICT infrastructure is undisturbed,
- the state guarantees protection of classified information and personal data of citizens,

- citizens, non-governmental organizations, and representatives of the mass media have access to public information [18].

It is not without reason that the concept of information warfare is becoming more and more popular - not only among theoreticians. Nor should it be surprising that it comes from military science.

As emphasized by Piotr Sienkiewicz and Halina Świeboda, there is no single, agreed definition of information warfare, but most of the proposed developments of this term contain common content. They all boil down to viewing information warfare as a conflict in which information is both a resource, an object of attack, and a weapon, and the conflict involves the physical destruction of the infrastructure used by the enemy for operational activities.

Currently, it is rightly believed that "cyberwar", "infowar", information warfare, cyberterrorism, "netwar", information warriors, information domination, cyberspace defense, or information chaos are just neologisms concerning the same a very broad concept of information age warfare [19].

The above explanation requires clarification. Indeed, P. Sienkiewicz himself proposes them, applying the principles of system analysis to information processes in the contemporary battlefield. In his opinion, the factor determining the results of the fight is the attitude of the fighting parties' knowledge. He defines information warfare as (...) the entirety of offensive and defensive activities necessary to obtain an information advantage over the enemy and to achieve the intended military (political) goals. The essence of information warfare understood in this way is 1-destruction (or degradation of value) of the opponent's information resources and the information systems used by him, 2-the security of one's own information resources and the information systems used.

Information potential as a factor of military potential is created by the information resources of the state defense system (data, information, knowledge) and information systems shaping the state's information infrastructure.

In the light of the above, it can therefore be concluded that information warfare is all offensive and defensive activities necessary to gain an advantage over the opponent and achieve the intended goals. The essence of this fight is, on the one hand, the destruction or degradation of the value of the opponent's information resources (including the criminal's resources) and the information systems used by them, and on the other - ensuring the security of their own information resources and information systems used. The elements of information warfare are physical destruction, security operations, psychological operations, sabotage, and electronic warfare. 
The tools used in this fight include:

- diplomatic,

- propaganda,

- psychological campaigns,

- activities influencing political or cultural processes,

- disinformation, manipulation of local media,

- infiltration of computer networks and databases.

Therefore, in information warfare, information is both a target of attack and a weapon, shield and sword, a resource, but it also includes the physical destruction of the infrastructure used by the opponent for operational activities, the destruction (or degradation of value) of the opponent's information resources and information systems used by him, security of own information resources and the information systems used.

In cyberspace, the information struggle takes the form of a "cyber conflict" in which success or failure depends on activities carried out in computer networks. Such a conflict can take the form of activism (non-destructive information and propaganda activities, e.g., on internet forums, chat rooms, social networks), hacktivism (activism and activities that disrupt the functioning of specific computer systems, e.g., by blocking access to servers) or cyberterrorism (politically motivated attacks on computers, networks or information systems in order to destroy infrastructure and force a government or organization to act or fail to act).

Therefore, cyberspace should be treated as a new operating environment in which the full range of information warfare is carried out using digitized information. Here you can deal with espionage, crime (attacks on bank accounts, extortion, fraud, etc.), terrorism, and actions requiring cyberspace to be treated as the fifth - after land, sea, air, and space - combat environment.

Such information warfare in cyberspace requires specific tools (sometimes colloquially called "hacking tools"). In practice, there are 20 basic tools used to carry out various types of attacks on IT systems:

- viruses, worms, and bacteria (malware) - programs that spread in the IT system and change the way it works or reproduces and takes up CPU memory, disk space, and other resources, and, as a result, block access to data,

- logic bombs - activating new functions of the computer's logical elements and leading to the destruction of hardware and software,

- Trojan horses - programs that enable actions to be taken in a computer system without the knowledge and consent of its legitimate user, e.g., deleting files, formatting disks, copying data, etc.,

- sampling - access to a computer by analyzing its characteristics,
- authentication - impersonating a person authorized to access the system,

- bypass - bypassing the process securing the system,

- reading - unauthorized access to information,

- copying - unauthorized copying of files,

- theft - taking over system resources by an unauthorized person without leaving a copy,

- modification - changing the data content or characteristics of the attack object,

- removal - the destruction of the attack object,

- malicious components - placing chips in computers that contain programs that allow unauthorized access to the system or create design defects,

- back door - software developers leaving the "gate" unknown to the user; unauthorized access to the system can be obtained from the rear doors,

- masquerade - pretending to be one of the system users attacking, e.g., by modifying packets during the connection,

- interception of transmission - gaining access to content sent between computers,

- wiretapping - tracking network traffic,

- van Eck receptor - the attacker watches on a separate monitor a replica of images appearing on the user's monitor of the attacked computer,

- Distributed Denial of Service-DDoS - blocking access to a website by sending a huge data packet from various sources to its address, which causes the server to freeze,

- e-mail bombing - sending a large amount of data to the user's mailbox, which causes its overflow,

- electromagnetic pulse - emission of electromagnetic radiation belonging to the radio spectrum, which destroys electronic devices and data [20].

The above considerations indicate the difficulties associated with attempts to create normative definitions of acts that cause threats to cyberspace. In the field of international law, such an attempt was made for the first time by the Council of Europe, which in 2001 adopted in Budapest the Convention on Cybercrime (hereinafter: the Budapest Convention). Defining particular terms, the Budapest Convention states in Art. 1 that:

- "Information system" means any device or group of interconnected or related devices, one or more of which, according to a program, performs automatic data processing;

- "Computer data" means any representation of facts, information, or concepts in a form suitable for processing in a computer system, including the relevant program causing the information system to perform a function;

- "Service provider" means any private or public entity that enables its service users to communicate through an information system, and any other entity that processes or 
stores computer data on behalf of such communication services or users of such services;

- "Traffic data" means any information technology data relating to communication through an information system generated by the information system that has formed the part in the communication chain, indicating its origin, destination, path, time, date, size, duration, or type of data services.

The Budapest Convention obliges the Member States to criminalize many acts committed in cyberspace. It breaks them down into four categories: crimes against the confidentiality, integrity, and availability of computer data and systems; computer crime; offenses due to the nature of the information contained therein and offenses related to the infringement of copyright and related rights.

In the first category, the abovementioned convention includes:

- $\quad$ illegal access understood as deliberate, unlawful access to all or part of an IT system. Parties may require that the offense must be committed by a breach of security, with intent to obtain computer data or with any other fraudulent intention, or with respect to an information system that is linked to another information system;

- illegal interception of data, i.e., intentional, unlawful interception by means of technical devices of non-public transmission of IT data to, from, or within an IT system, including electromagnetic emissions from the information system transmitting such IT data. Parties may require that the offense must be committed with fraudulent intent or in connection with an information system that is linked to another information system;

- data integrity breach understood as deliberate, unlawful destruction, deletion, damaging, changing, or deleting IT data A party may reserve the right to require that the conduct must result in serious harm;

- violation of the integrity of the system, i.e., deliberate, unlawful, serious interference with the functioning of the IT system by introducing, transmitting, destroying, deleting, damaging, changing, or deleting IT data;

- improper use of devices understood as deliberate and unlawful activities consisting in the production, sale, acquisition with the intention of using, importing, distributing, or otherwise sharing.

The second category is computer crime, and thus computer counterfeit and computer fraud. Computer counterfeit is a deliberate, unlawful introduction and modification, deletion, or deletion of computer data, resulting in the creation of inauthentic data, which the perpetrator intends to be recognized or used for lawful purposes as authentic, regardless of whether they are understood or understood. and whether they can be read directly. A party may require that criminal liability relates to an act of fraudulent or similar fraudulent intention. On the other hand, computer fraud is considered to be a computer fraud by the willful, unlawful loss of property by another person by introducing, modifying, deleting, or deleting computer data or any interference with the functioning of a computer system with the intention of fraud or fraudulent intention to obtain economic benefits for himself or another person.

Offenses due to the nature of the information contained (third category) concern acts related to the unlawful and deliberate production, offering, sharing, acquisition and possession of child pornography by means of an information system. The fourth category concerns infringement of copyright and related rights with the use of an IT system.

In a similar way, acts against cyberspace security are defined by European Union law, the so-called directive on attacks against information systems. Directive 2013/40 / EU obliges the Member States of the European Union to take steps to punish the following offenses as crimes:

- unlawful access to information systems, i.e., deliberate and unlawful access to all or any part of an information system, when it was committed in breach of security measures, at least in cases that are not minor;

- unlawful interference with systems, i.e., deliberate and unlawful access to all or any part of the IT system, when this crime was committed in violation of security measures, at least in cases that are not minor;

- unlawful interference with data, understood as deliberate and unlawful deletion, damage, deterioration, modification or elimination of computer data in the IT system or making them unavailable, at least in cases that are not minor;

- unlawful interception, i.e., deliberate and unlawful interception by means of technical means of non-public transfers of computer data to, from, or within an IT system, including electromagnetic emissions from an information system containing such computer data, at least in cases which are not less weight.

There is also entitled tools for committing crimes, acts involving the deliberate production, sale, supply for use and import, dissemination or otherwise making available one of the following tools: a computer program designed or adapted mainly to commit one of the abovementioned crimes, a computer password, an access code or similar data allowing access to all or part of an IT system. As in the case of other acts, the condition is the unlawfulness and intention of the perpetrator's actions and that the act does not constitute a minor event.

The enhanced functionality of UASs and their modern technological advances, especially considering wireless communication interfaces, increased the scope of their potential usage. In general, the communication flow takes place between the drones mutually and between the drones and ground 
stations. Some of the commonly used communication forms between drones and ground stations are Wi-Fi, GPS, Bluetooth, Infrared, and ZigBee, which are sensitive to attacks [21]. Drones are connected to computers and networks, store many data, and transmit information. Due to critical information being part of that flow, the UASs are a desirable target for malicious actors.

Today, UAS's are devices whose use on the battlefield is constantly growing as well. But also, their popularity increases the risk of destructive cyber-attacks that may affect complex networks and systems. In the report, RAND Corporation experts described the possible threats resulting from the use of drones during operations and presented recommendations, the implementation of which should realistically increase the level of cybersecurity of unmanned aerial systems.

In the world of constant and dynamic technological changes, minimizing vulnerability is an endless race with opponents, reads the report "How to Analyze the Cyber Threat from Drones" prepared by specialists from RAND Corporation. In the document, specialists analyzed the issue of cybersecurity in relation to the growing use of UAS [22].

Experts indicate that today UAS has become more common, more accessible, and more useful due to new possibilities, such as increased data collection capabilities and autonomous operation of operations. In this way, UAS can be both a target of a cyber-attack and an effective weapon.

The report presents the security implications of the rapid development of UAS technology, focusing in particular on vulnerabilities and future trends. "As UAS become more common, both the likelihood of a cyber-attack and the potential security implications are increasing," the document said. According to data presented by specialists, estimated UAS sales will exceed $\$ 20$ billion by the end of 2021 .

Experts also attempted to identify possible trends and potential consequences for operators. Specialists predict that drones will be even more integrated with security systems. New developments in UAS technology, including the introduction of more autonomous control software and the ability to create a swarm of drones via mobile networks, increase the scope and advancement of potential cyber-attacks.

The report shows that entities using UAS may become victims of cyber-attacks, including data breach incidents. This is due to the fact that the control of these devices takes place from a location center located in a specific place on earth. This is where sensitive data and wireless networks are found that are attractive to hackers. Moreover, specialists have no doubts that "UAS controllers exhibit vulnerabilities and are therefore an access point for malicious actors".

Experts emphasize that the incident does not have to be carried out using the targeted networks and systems directly related to the device. They indicate that hackers can use, inter alia, the private equipment of the drone operator, which, for example, logs into a specific network responsible for UAS settings.
RAND Corporation experts clearly indicate that the attacked drones may affect the security of the US Department of Homeland Security. Experts explain that the incident can effectively limit the intelligence, surveillance, and reconnaissance capabilities of the services and thus contribute to the development of crime.

It is also alarming that an advanced cyber-attack against the equipment used by the American Cybersecurity and Infrastructure Security Agency (CISA) is possible. The drones at the agency's disposal can be "hijacked" by hackers and used to directly destroy elements of critical infrastructure.

Moreover, a cyber-attack on UAS systems used by the Federal Emergency Management Agency (FEMA) may reduce the agency's ability to identify vulnerable areas and people in danger or health, warn RAND Corporation specialists.

The report also includes recommendations, the implementation of which should really contribute to increasing the cybersecurity of drones and related networks and systems. Experts indicate that the first step to protect against cyber-attacks against UAS should be primarily to create a map of threatened areas and to create an effective risk neutralization plan. It is also necessary to establish cooperation with cybersecurity specialists who have appropriate experience and knowledge to improve the quality of security. At the state level, the priority seems to be to tighten the relationship between state administration entities and law enforcement agencies in order to create a common cyber strategy dedicated to UAS.

It is equally important to invest in regular testing of equipment in cross-sectoral cooperation (state, private companies, laboratories, research centers, etc.), as it enables the creation of universal security and protection protocols that could be implemented on a larger scale.

The key element is also the identification of security gaps and taking effective actions to eliminate them. In this regard, it is necessary to constantly monitor UAS systems and follow the development of this technology. The "coordinated and constantly updated system of monitoring and intervention seems to be indispensable because even the latest solutions do not guarantee full resistance to every cyber-attack".

Moreover, experts indicate that in addition, the possible consequences of the spread of UAS technology should be anticipated. "As drones are used in a wider range of activities, the number of lawful uses of UAS at any given time will increase," the report reads. - "Therefore, from the point of view of risk reduction, one of the most important tasks in the area of UAS operation will be to distinguish and define legal operations from illegal activities using drones".

It needs to be noted that even if there are many advantages of using drones, they remain vulnerable, as there is no pilot onboard to monitor any unusual situations during their operations. As there is no manual control, it is possible to access data for the malicious actors and insert fraudulent information into drones. This may result in reprogramming drones, doing irreversible damage, or even taking full control over them. 
Cyber attackers, utilizing the UASs, can potentially exploit points of access, unsecured networks, or other devices wirelessly. By doing so, the malicious actors may execute malicious code, inject malware, perform a man-in-the-middle attack, and much more. It is also possible that a drone can be hacked by using another drone, which can be possible by using a Wi-Fi network. For example, in 2014, researchers from Sensepoint security firm developed an application that was installed on a drone. Through an open Wi-Fi network, a flying drone with that application was able to steal users' data, like usernames, passwords, credit card details, from devices connected to the network [23].

As another example, security analysts claimed and proved the ability to hijack and even take control of a drone mid-flight [24]. By hijacking a drone, the malicious actor can potentially extract data related to the flight route, gain access to pictures and videos taken during the flight, as well as control the movement of a drone, ultimately having an impact on public safety as well as the safety of the manned aircraft and its personnel. Accessing the data stored on the drone is critical and may endanger the security of the user's data and privacy.

The security concerns related to drones and their dependency on GPS need to be addressed. As GPS is used for drones' navigation and no encryption is in place, it is an easy target for attackers. Losing control of drones by a GPS spoofing attack may result in massive harm. For example, it was claimed that in December 2011, Iranian forces took control over a Lockheed Martin RQ-170 Sentinel drone, which belonged to the United States Air Force. The explanation of taking control of a drone was a potential GPS spoofing attack [25].

However, there are no confirmed incidents of exploiting wireless systems by using drones; the research community was able to demonstrate such a possibility. In 2015, researchers from Singapore, using 3G or $4 \mathrm{G}$ connection with a smartphone being attached to a drone and having installed applications with the ability to detect printers connected to unsecured wireless networks, were able to intercept a document sent to a printer and save a copy. The document was still sent for printing; thus, the document owner was not aware of the attack [26]. The claim of other researchers in 2016 was related to the compromising of smart lightbulbs inside the building by a piece of equipment attached to a drone. The attack was performed by flying a drone at a range of $350 \mathrm{~m}$ to control the lightbulbs by firmware updates [27].

Taking into consideration the requirements for the manufacturers to ensure the systems built into the UAS are secure and cannot be exploited by the users, the malicious actors still find a way to perform an attack. Moreover, it needs to be considered that there is a huge number of drones with outdated security controls or so-called self-assembled drones without the required level of security controls, posing a high risk.
Cyber threats related to the operation of UASs are continually evolving with the development of technology, a higher level of digitization, and expanding capabilities of drones.

Cyberspace has also become an environment of combat and war. In this context, it is necessary to emphasize the problem of the international legal assessment of the means of information warfare waged in this space. Its rank and importance - for example in the case of technological development and the increasing importance of digital information - will increase in the foreseeable future. Several elements should be mentioned here. Firstly, there is no doubt that information warfare in cyberspace within the framework of the ongoing armed conflict is an inherent part of this conflict. Secondly, information warfare waged in cyberspace spontaneously, i.e., in conditions of peace - without military operations, is gaining more and more importance. In such a fight, the objectives do not have a direct military significance (as, for example, in an armed conflict, cyber-attacks on the enemy's command and communication systems) but belong to the category of the state's critical infrastructure. Such attacks may cause threats to international security (global information security), destabilization of critical infrastructure, disruptions in the functioning of public administration, economic losses (inhibition of the development of companies and enterprises), or even personal losses of citizens. The scale of the attack and the losses are important.

Third, cyberspace is used by criminals acting only for profit. This aspect has been discussed above.

The fact remains that the problem of self-contained information warfare in cyberspace is not at all referred to in the applicable international law. When analyzing hypothetical cyber-attacks on the state's critical infrastructure, the following situations can be identified:

- the attacker is known, and the state (victim) takes military action against him,

- in a similar situation, the state (the victim) responds with a cyber-attack on the aggressor's infrastructure,

- the attacker is unknown, it is possible to identify only the IP address, and the attacked country, using hacking tools, takes control of the hard disk and, for example, destroys the data stored there,

- the attacker is not identified at all, which means that the state (the victim) does not know by whom he was attacked and does not know who to retaliate against.

Military responses to cyber-attacks are already envisaged in states' strategies. For example, the United States reserves the right to respond to such threats by all necessary and appropriate means. In Polish legislation, attacks from cyberspace were treated on a par with an armed attack on the territory of the Republic of Poland or terrorist attacks as an external threat to the state justifying the introduction of martial law. 
Do such actions comply with international law? While the case of Poland is beyond dispute (the introduction of martial law does not mean taking military action), the possibility of taking a strictly military or only cybernetic retaliation raises doubts. It is not clear (at least it does not emphatically result from the applicable international law) whether a cyber-attack on critical infrastructure can be considered a justification for taking actions under Art. 51 of the United Nations Charter (self-defense), and therefore - military actions in self-defense. Undoubtedly, it would have to be a serious attack, i.e., not an incident, but an action involving significant losses in the material sphere and human casualties (e.g., leading to an explosion of a nuclear power plant). The consequence of this would be to consider such an attack an armed attack, or at least a threat to international peace and security. As it stands today, only the United Nations Security Council could do so, as it happened after the terrorist attacks on September 11, 2001.

The attacked state's reaction to launch a retaliatory cyberattack would belong to the so-called countermeasures, formerly known as repressions. When applying them, the principle of proportionality of the retaliatory measure to the infringement committed and the aim pursued should be respected, and the aggrieved State should make a claim for reparation before launching them. The doctrine of international law emphasizes that repression as a retaliatory measure consists in a temporary suspension of the application of a specific rule of international law by the aggrieved state, undertaken in response to actions contrary to the international law of another state. Under normal circumstances, measures used as repressive measures are in conflict with international law, and only the prior action of another state justifies retaliation against them. The applied repression may not, however, violate the prohibition of the threat or use of force, fundamental human rights, humanitarian obligations, and other obligations resulting from peremptory norms (i.e., norms of the "iuris cogentis" type, which are absolutely binding) of general international law [28].

The third case of a hypothetical attack is extremely difficult to classify under international law. Such an attack would rather be a convention offense, and the state's reaction described above is very difficult to classify under international law.

The issues raised require urgent solutions. It is difficult to accept the dictatorship of the forces that do not recognize any rules of conflict, including armed ones. It is also difficult to allow a situation in which states are forced to break applicable international law. The application of the principle of "necessity does not know the law", mentioned several times, is a straightforward way to degrade the role of international law and thus - to anarchize international relations. This rule can only be considered as an exception in emergency situations requiring a quick and decisive solution. However, it should never be included in the set of fundamental principles of international law.

\section{Overview of the Civil Aviation Cybersecurity Framework and the Current Activities Relative to the UAS}

\subsection{International (ICAO) Level}

The UAS under the international regime of air law is considered an aircraft, therefore most of the cybersecurity provisions addressing aviation cybersecurity should also apply to the operations of UAS. In terms of the aviation cybersecurity framework, many actions have already been taken. It is worth then to consider those actions further and have a look at possible applicability to drones.

Based on international air law, civil aviation is protected against cyber threats by many different provisions. For example, international air law conventions address some acts of unlawful interference. One of the conventions that indirectly refers to cyber-attacks against international civil aviation is the Beijing Convention of 2010 which states that any person who unlawfully and intentionally destroys or damages air navigation facilities or interferes with their operation, and if any such act is likely to endanger the safety of aircraft in flight, commits an offense. Moreover, it further states that an offense may be also committed by communications of false information to endanger the safety of an aircraft [29]. Furthermore, the Beijing Protocol of 2010, supplementing the Convention for the Suppression of Unlawful Seizure of Aircraft signed at The Hague on 16 December 1970, to suppress unlawful acts of seizure or exercise of control of aircraft and to improve its effectiveness, introduced the offense of unlawful and intentional seizure or taking control of an aircraft in service by any technological means [30]. Both, the Beijing Convention and Beijing Protocol, however indirectly, unquestionably apply, inter alia, to cyber-attacks; however, they solely identify the offenses against the safety of airborne aircraft. Since 2010, there has been no change in the international conventions protecting civil aviation against acts of unlawful interference. Taking into consideration the emerging cyber threats, industry digitalization, as well as the integration of the UAS into the airspace, the legal instruments should be further analyzed, and the possibility adapted to the current status of digitalization and fact of emerging cyber threats.

One of the international leaders in the civil aviation industry, that constantly works in order to address cyber threats, is the International Civil Aviation Organization (ICAO). This organization is regulated by the civil aviation legal regime under the Chicago Convention of 1944. The ICAO was established back then with a primary aim to address principles for international air navigation and assist Member States in the process of international air transport development [31]. ICAO, based on the Chicago Convention, is an international body responsible for the implementation of new regulations, Standards and Recommended Practices (SARPs) incorporated 
into nineteen Annexes to this convention. Thus, in 2012, during the ICAO Twelfth Air Navigation Conference (AN-Conf/ 12) [32], it was recommended by the conference that ICAO, in order to evaluate the status of cybersecurity within the industry and further address this challenge, should establish an appropriate mechanism for this task. In order to coordinate this task, ICAO established the Secretariat Study Group on Cybersecurity (SSGC) and related working groups to address cybersecurity issues within civil aviation. Through this study group, the ICAO collaborates with the Member States as well as leading industry stakeholders to develop a roadmap for necessary actions and the development of cybersecurity provisions [33].

As it was mentioned before, the ICAO is responsible for the implementation of the SARPs. In 2014, the ICAO adopted two recommended practices within Annex 17 of the Chicago Convention, to introduce measures relative to the cyber threats. Following the developments in cybersecurity, as well as the work of SSGC, in 2018, one of the recommended practices has been upgraded to a standard by the Amendment 16th of Annex 17. Standard 4.9.1, the only standard within the ICAO framework addressing cybersecurity, requires the ICAO Member States to ensure that operators and/or aviation entities, according to the relevant national civil aviation security documentation, identify their critical information, communications technology systems, and data [34]. Based on the Standard 4.9.1. the ICAO Member States need to adapt the national regulations and implement this standard to address measures relative to cyber threats.

Moving forward, the Assembly Resolution A39-19 tasked the ICAO Member States as well as the industry stakeholders to work together on a coordinated cybersecurity approach. This should include strategy, policy-making, and mechanisms for information sharing in order to enable the identification of vulnerabilities within the broad industry. Moreover, it addressed that the Member States and aviation stakeholders, including the international organizations, should establish actions in order to counter emerging cyber threats within the industry. It emphasized that this should be done by establishing and following a cross-cutting, horizontal, and collaborative approach [35]. Following the outcomes and collaboration, the ICAO Assembly 40th Session in 2019, appreciated all the efforts, especially through the endorsement of the first worldwide Aviation Cybersecurity Strategy produced by ICAO SSGC with support from the Member States and industry [36]. Moreover, it was underlined that the next essential step is to provide the Member States with the appropriate action plan for the Strategy implementation [37], which is a living document and has been adopted by the ICAO Council in late 2020.

Moreover, at the ICAO level, some works directly focused on drones with the need to understand the challenges associated with the operations of drones. One of the activities related to the drones is the Remotely Piloted Aircraft Systems Panel (RPASP), which is consisted of experts nominated by the ICAO Member States and international organization with the terms of reference to coordinate the work relative to the development of SARPs (Standards and Recommended Practices), guidance material and procedures in order to ensure the safe, secure and efficient integration of the drones into the non-segregated airspace. This Panel engages in many different areas; however, it is not clear to what extent, and if so, the Panel addresses issues relative to cybersecurity and drones [38]. The only document, identified with the Panel that addresses cybersecurity is the Remotely Piloted Aircraft System (RPAS) Concept of Operations (CONOPS) for International IFR Operations. This document states that cybersecurity needs to be assures if it comes to remotely piloted aircraft. However, it should be noted that this document is not a final and approved version of the ICAO document and the works are ongoing [39].

The Task Force on UAS for Humanitarian Aid and Development (TF-UHAD), which is another activity of ICAO on the drones, was established to support the ICAO Secretariat in terms of providing the necessary guidance to the Member States, international organizations as well as the UAS industry for the operations of the UAS used for the humanitarian aid and development [40].

With regard to the work of the TF-UHAD, the ICAO developed the guidance material entitled Unmanned Aircraft Systems (UAS) for Humanitarian Aid and Emergency Response Guidance (U-AID), which addresses some recommendations on cybersecurity. Those recommendations directly refer to the system specifications for air, ground, and cyber. It reads that the flight systems are composed of three different sub-systems like software, hardware, and communication. Each system must include the details relative to performance, reliability, and potential failures. Therefore, in terms of cybersecurity, the latest version of the software must be validated by any certification information and safety assurance program, which has been loaded into the UAS [41].

Another group established by ICAO on the UAS is the Unmanned Aircraft Systems Advisory Group (UAS-AG), which aims to support the ICAO Secretariat in the development of the guidance material and provisions to be used by the Member States in order to regulate the UAS. The key support of this group focuses on providing support to the collaboration on global safety. Moreover, the UAS-AG is tasked to help the ICAO establish a common global framework and principles for unmanned aircraft traffic management (UTM) referring to the technical, operational, and legal issues [42]. Therefore, this group should also look into the issues relative to cybersecurity. Relative to the work of the UAS-AG on the UTM, the document entitled the Unmanned Aircraft Systems Traffic Management (UTM) - A Common Framework with Core Principles for Global Harmonization (Edition 3) was 
developed by ICAO in order to provide the framework, and core principles on the UTM systems addressed to the Member States planning on implementation of the UTM system. This document addresses cybersecurity aspects, especially underlying the significant risks and vulnerabilities associated with the UTM and the UAS. It directly considers the C2 Link disruptions, Global Navigation Satellite System (GNSS) jamming and/or spoofing attacks, as well as the manipulation of information exchanged between different UASs and between the UAS and UTM [43].

\subsection{Regional (European Union) Level}

In Europe, the complex rulemaking task addressing the safety of civil aviation, including aspects of cybersecurity, is led by the European Aviation Safety Agency (EASA). The main goal of EASA is to ensure that the Europen aviation ecosystem is safe, secure, and resilient [44]. With the amendment of the socalled Basic Regulation (EU) 216/2008, the new Regulation (EU) 2018/1139 [45], for the very first time directly referred with its provisions to cybersecurity and established that the coordinating role to collaborate with the industry stakeholders on cybersecurity issues will belong to EASA [46]. Based on this, the EASA established two rulemaking proceedings in order to implement new provisions on cybersecurity. The first one, the Aircraft Cybersecurity (RMT.0648), intends to address cybersecurity provisions through different certification specifications in order to mitigate cyber threats impacting safety [47]. The second one, the management of information security risks (RMT.0720) is related to aeronautical information systems [48]. None of the rulemakings will apply to the UAS.

In terms of the specific UAS regulations at the European level, there are some already in force. For example, the Commission Delegated Regulation (EU) 2019/945, which lays down the requirements for the design and manufacture of the UAS. This regulation also defines the types of the UAS (including design, production, and maintenance) for which the certification is required. However, the regulation provides the requirements for the design and manufacture of the UAS; there is not a lot of information regarding cybersecurity. It just refers to the Regulation (EU) 2018/1139 and its Article 55 as per the requirements in terms of risk mitigation pertaining to safety, privacy, and data protection [49].

The Regulation (EU) 2019/945 was amended by the Commission Delegated Regulation (EU) 2020/1058 [50]. It needs to be noted that the new regulation has not introduced any additional provisions that would refer to cybersecurity.

Another regulation at the European Union level on the UAS that needs to be mentioned is the Commission Implementing Regulation (EU) 2019/947, which introduced provisions for the UAS operations and its personnel. In its Article 19 relative to the safety information, it states that the
Agency, i.e., EASA, the competent authority, “(...) shall take the necessary measures to address any safety issues on the best available evidence and analysis, taking into account interdependencies between the different domains of aviation safety, and between aviation safety, cybersecurity and other technical domains of aviation regulation" [51]. This is the only provision within this regulation that directly refers to cybersecurity; however, it should be noted that this provision is related to the actions that should be taken by EASA.

\subsection{National (Republic of Poland) Level}

In terms of the national level, considering the Republic of Poland, civil aviation is regulated by the Act of 3 July 2002 - Aviation Law [52]. This regulation also addresses matters related to UAS operations. It needs to be underlined that this regulation has no reference to the cybersecurity issues within the civil aviation industry.

In the Republic of Poland, the regulations addressing cybersecurity is the Act of 5 July 2018 on the National Cybersecurity System. It applies to different industries, including civil aviation. Therefore, it should also apply to the UAS industry and operations. However, it needs to be underlined that the Act on the National Cybersecurity System provides very little guidance in terms of civil aviation [53].

This should be changed and more cybersecurity provisions, especially related to the UAS, incorporated within the national legislation. Moreover, the national regulators should provide specific guidance and recommendations on the UAS and cybersecurity for their operators as the actions need to be taken in order to mitigate the cyber risks. This would require closer collaboration between the different stakeholders, including those representing civil aviation and the UAS, regulators, international organizations and associations, as well as original equipment manufacturers and system suppliers.

\section{Proposed Recommendations}

The civil aviation industry and UAS industry need to be aware of the importance of cybersecurity within the UAS operations as well as emerging cyber threats associated with the increasing technology development, digitalization, and connectivity. Moreover, it should be underlined that in cybersecurity. The integration itself of the UAS into the civil aviation airspace brings a lot of challenges in terms of cybersecurity as well as new threats to the industry. It is critical for both industries to ensure efficient and safe integration. As was discussed, the continuous technology development and enhanced functionalities built into drones create new threat vectors that malicious actors will try to exploit. 
However, there is already in place a cybersecurity framework for the civil aviation industry, which is constantly developing and gaining maturity, a higher level of awareness of UAS is required in order to take action before their integration into airspace. Therefore, to facilitate that process, and ensure the cybersecurity is at the appropriate level, the following should be considered:

- Establishing an appropriate level of understanding relative to cybersecurity and drones between different stakeholders.

- Conducting the awareness campaigns for the aviation and UAS industries on cybersecurity by the leading organizations and stakeholders;

- Engagement of both industries with the research communities, academia on the potential cyber risks associated with the usage of the UAS;

- Establishing a trusted and dialogue (possibly through different working groups or forums) among the UAS manufacturers, operators as well as regulators, or other relevant organizations, on how to ensure the confidentiality, integrity, and availability of systems and data are protected, which will create proper lines of communication between different stakeholders;

- Ensuring there is a right level of regulations and/or standards and recommended practices, complemented by the guidance material, for the UAS that address cybersecurity issues at international, regional, and national levels;

- Establishing proper mechanisms for the information sharing between appropriate stakeholders, define the type of information that should be shared (e.g., vulnerabilities, cyber threats, lessons learned from previous attacks).

- Developing appropriate education, training programs, and tabletop exercises to address the cybersecurity challenges of the UAS.

\section{Conclusions}

The emergence and development of the information society brought - apart from indisputable benefits - also many threats to the security of the state and its citizens. Most of them are related to the development of cyberspace, as well as to the increasing and nowadays essential role of information, understood as a strategic resource. It is no wonder then that these threats fall into the category of information warfare.

This creates new challenges for the services responsible for state security. When undertaking information warfare in cyberspace, they must have both defensive and offensive abilities, and therefore - in other words also the ability to deter a potential attacker, regardless of whether we are dealing with a cyber-attack by the state, non-state entity, or against the crime of espionage in cyberspace, or we are dealing with a criminal using modern communication technologies.

The emerging enhancements in technology and functionality of the UAS, as well as, constantly growing number of interconnected systems and devices, bring a lot of challenges in terms of cybersecurity. This process creates some possibilities for malicious actors to exploit vulnerabilities and conduct successful cyber-attacks. It should be also noted that different motivations and ways stand behind them.

Since the UAS under the international air law regime is considered an aircraft, some provisions of the aviation cybersecurity framework should also apply to the UAS. However, there is already some level of maturity within the aviation cybersecurity framework, there still few provisions that would apply directly to the UAS.

This paper explained the rapid development of the UAS industry and emerging threats related to its development. Moreover, an analysis of the potential cyber threats with examples was conducted. Further, the paper addressed the level of the civil aviation cybersecurity framework's maturity. This was followed by several suggestions that should be further considered.

Authors Contributions All authors contributed to the study conception and design. Material preparation, data collection and analysis were performed by Mr. Mariusz Pyzynski, Mr. Tomasz Balcerzak. The first draft of the manuscript was written by Mr. Mariusz Pyzynski and Mr. Tomasz Balcerzak and all authors commented on previous versions of the manuscript. All authors read and approved the final manuscript.

The list of authors is the following:

1. Mr. M. Pyzynski is a Ph.D. Candidate in the Institute of Air and Space Law. Faculty of Law and Administration, Lazarski University in Warsaw, Poland (e-mail: mariusz.pyzynski@gmail.com).

2. Mr. T. Balcerzak, Ph.D., is adjunct at Lazarski University in Warsaw, Poland, Faculty of Law and Administration (e-mail: tomasz.balcerzak@lazarski.pl).

Funding The authors confirm there was no funding involved in the research in order to prepare this manuscript.

Availability of Data and Materials N/A

\section{Declarations}

Ethical Approval This manuscript has not been submitted to more than one journal for simultaneous consideration. The version of the submitted paper appeared in the Proceedings of the 2020 International Conference on Unmanned Aircraft Systems (ICUAS'20), Athens, Greece. However, it does not overlap more than $30 \%$ of the paper presented during ICUAS'20.

Consent to Participate All of the authors declare the consent to participate in this manuscript.

Consent to Publish All of the authors declare the consent to publish this manuscript. 
Competing Interests Mr. M. Pyzynski is also the Assistant, Aviation Security at the International Air Transport Association (IATA). Therefore, the author represents in this paper solely his own position, which shall not be associated with the organization of employment.

Open Access This article is licensed under a Creative Commons Attribution 4.0 International License, which permits use, sharing, adaptation, distribution and reproduction in any medium or format, as long as you give appropriate credit to the original author(s) and the source, provide a link to the Creative Commons licence, and indicate if changes were made. The images or other third party material in this article are included in the article's Creative Commons licence, unless indicated otherwise in a credit line to the material. If material is not included in the article's Creative Commons licence and your intended use is not permitted by statutory regulation or exceeds the permitted use, you will need to obtain permission directly from the copyright holder. To view a copy of this licence, visit http://creativecommons.org/licenses/by/4.0/.

\section{References}

1. M. Huttunen, "Civil Unmanned Aircraft Systems and Security: the European Approach", Journal of Transportation Security, September 2019, p.1

2. The Economist, "Technology Quarterly: Taking Flight", 2017, online: www.economist.com/technology-quarterly/2017-06-08/civilian-drones, accessed on 30/11/2020

3. D. F. Katz, J. Pringle, G. J. Guillot, "Cybersecurity for Drones: don't Fly Blind”, Lexology, November 2019

4. E. Vattapparamban, I. Güvenç, A. I. Yurekli, K. Akkaya and S. Uluağaç, "Drones for smart cities: Issues in cybersecurity, privacy, and public safety," 2016 International Wireless Communications and Mobile Computing Conference (IWCMC), Paphos, 2016, pp. 216-221

5. R. Altawy, Amr M. Youssef, "Security, privacy, and safety aspects of civilian drones: a survey", ACM Transactions on Cyber-Physical Systems, November 2016, pp. 1-25

6. B.I. Scott (ed.), "The law of unmanned aircraft systems. An introduction to the current and future regulation under national, regional and international law", Kluwer Law International BV, The Netherlands, 2016

7. Homeland Security, National Protection and Programs Directorate, Office of Cyber and Infrastructure Analysis (OCIA), "Cybersecurity risks posed by unmanned aircraft systems", May 2018, online: https://www.eisac.com/cartella/Asset/

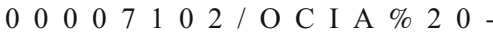

$\% 20$ Cybersecurity $\% 20$ Risks $\% 20$ Posed $\% 20$ by\%20Unmanned\%20Aircraft\%20Systems.pdf?parent=115994, accessed on 30/11/ 2020

8. ICAO Cir 328, Unmanned Aircraft Systems (UAS), 2011

9. ICAO, Doc7300/9, Convention on International Civil Aviation, online: https://www.icao.int/publications/Documents/ 7300 cons.pdf, accessed on 30/11/2020

10. R. Doss, S. Piramuthu, W. Zhou, "Future Network Systems and Security: 5th International Conference, FNSS 2019, Melbourne, VIC, Australia, November 27-29, 2019, Proceedings"

11. W. Gibson, ,Neuromancer”, Canada, 1984

12. M. Madej, Rewolucja informatyczna - istota, przejawy oraz wpływ na postrzeganie bezpieczeństwa państw i systemu międzynarodowego, w: Bezpieczeństwo teleinformatyczne państwa, M. Madej, M. Terlikowski (red.), Warszawa 2009, s. 28

13. M. Madej, Rewolucja informatyczna - istota, przejawy oraz wpływ na postrzeganie bezpieczeństwa państw i systemu międzynarodowego, w: Bezpieczeństwo teleinformatyczne państwa, M. Madej, M. Terlikowski (red.), Warszawa 2009, s. 28

14. Art. 2 ust. 1 b Ustawy $z$ dnia 29 sierpnia 2002 r. o stanie wojennym oraz o kompetencjach Naczelnego Dowódcy Sił Zbrojnych i zasadach jego podległości konstytucyjnym organom Rzeczypospolitej Polskiej (tekst jednolity: Dz.U. z 2014 poz. 1815 , ze zm)

15. T. Aleksandrowicz, Świat w sieci. Państwa - społeczeństwa ludzie. W poszukiwaniu nowego paradygmatu bezpieczeństwa narodowego, Warszawa 2014

16. The National Strategy to Secure Cyberspace [online], February 2003, http://www.hsdl.org/?view\&- did=1040, accessed on 25/11/ 2020

17. B. Pacek, R. Hoffman, Działania sił zbrojnych w cyberprzestrzeni, Warszawa 2013

18. E. Nowak, M. Nowak, Zarys teorii bezpieczeństwa narodowego, Warszawa 2011

19. P. Sienkiewicz, H. Świeboda, Sieci teleinformatyczne jako instrument państwa - zjawisko walki informacyjnej, in: Bezpieczeństwo teleinformatyczne państwa

20. E. Lichocki, Model systemu zarządzania kryzysowego w warunkach zagrożeń cyberterrorystycznych dla bezpieczeństwa informacyjnego Sił Zbrojnych RP, Wydział Bezpieczeństwa Narodowego Akademii Obrony Narodowej, Warszawa 2009

21. C. Rani, H. Modares, R. Sriram, D. Mikulski, F. Lewis, "Security of Unmanned Aerial Vehicle Systems against Cyber-Physical Attacks", The Journal of Defense Modeling and Simulation: Applications, Methodology, Technology, 2015

22. T. Hamilton, D. Ochmanek, "Operating Low-Cost, Reusable Unmanned Aerial Vehicles in Contested Environments" Published by the RAND Corporation, Santa Monica, USA 2020

23. M. Geoff, E. Steuter, "Drone Nation: The Political Economy of America's New Way of War", 2016, p. 63

24. M.H. Au, S.M. Yiu, J. Li, X. Luo, C. Wang, A. Castiglione, K. Kluczniak, "Network and System Security: 12th International Conference, NSS 2018, Hong Kong, China, August 27-29, 2018, Proceedings"

25. Yu-Min, J., Teck-Boon Tan, T.: Smart cities: a new age of digital insecurity, survival. 60, 91-106 (2018)

26. D. Barnhizer, D. Barnhizer, "The Artificial Intelligence Contagion: Can Democracy Withstand the Imminent Transformation of Work, Wealth and the Social Order?", 2019

27. R. Abeyrante, "The Beijing Convention of 2010 on the suppression of unlawful acts relating to international civil aviation - an interpretative study", Journal of Transportation Security, 2011, Volume 4 (2), p.132

28. Aleksandrowicz T., Strategie bezpieczeństwa w cyberprzestrzeni. Cyberwojny, w: Sieciocentryczne bezpieczeństwo. Wojna, pokój i terroryzm w epoce informacji, K. Liedel, P. Piasecka, T. Aleksandrowicz (red.), Warszawa 2014, Difin

29. Beijing Protocol 2010, Supplementary to the convention for the suppression of unlawful seizure of aircraft, online: https:// w w w. i c a o.int/s e cretariat/1 e ga $1 / \mathrm{Docs} /$ beijing protocol_multi.pdfaccessed on 30/11/2020

30. ICAO, Convention on International Civil Aviation, signed at Chicago on 7 December 1944, ICAO Doc. 7300/9 (2006), online: https://www.icao.int/publications/Documents/7300_cons.pdf, accessed on 21/02/2020. The Chicago Convention came into force on 4 April 1947

31. ICAO, Twelfth Air Navigation Conference, online: ICAO https:// www.icao.int/Meetings/anconf12/pages/default.aspx, accessed on $30 / 11 / 2020$

32. ICAO, Annex 17 to the Convention on Civil Aviation, Security: Safeguarding International Civil Aviation against Acts of Unlawful Interference, 10th Edition, Amendment 16, 2018 
33. ICAO, "Aviation Cybersecurity Strategy", October 2019, online: https://www.icao.int/cybersecurity/Documents/ AVIATION\%20CYBERSECURITY\%20STRATEGY.EN.pdf, accessed on $30 / 11 / 2020$

34. ICAO, Assembly Resolution, Addressing Cybersecurity in Civil Aviation, Appendix A39-ICAO Doc. WP/17 EX/5 30/5/16, 2016

35. M. Pyzynski, "Current Approach to Secure the Civil Aviation Industry against Cyber Threats", Prawo a nowoczesność. Wyzwania - problemy - nadzieje, Warsaw 2019, pp. 219-229

36. ICAO, "Assembly Resolutions in Force", Doc 101140, online: https://www.icao.int/publications/Documents/10140_en.pdf, accessed on 30/11/2020

37. Coman-Kund, F.: European Union Agencies as Global Actors: a Legal Study of the European Aviation Safety Agency, Frontex and Europol, pp. 120-123. Routledge Tylor \& Francis Group, London and New York (2018)

38. ICAO, Remotely Piloted Aircraft Systems Panel (RPASP), online: https://www.icao.int/safety/UA/Pages/Remotely-Piloted-AircraftSystems-Panel-(RPASP).aspx, accessed on 29/11/2020

39. ICAO, Remotely Piloted Aircraft System (RPAS) Concept of Operations (CONOPS) for International IFR Operations, online: https://www.icao.int/safety/UA/Documents/ ICAO\%20RPAS\%20CONOPS.pdf, accessed on 29/11/2020

40. ICAO, Task Force on Unmanned Aircraft Systems for Humanitarian Aid and Development (TF-UHAD), online: https:// www.icao.int/safety/UA/Pages/Task-Force-on-UnmannedAircraft-Systems-for-Humanitarian-Aid-and-Development-(TFUHAD).aspx, accessed on 29/11/2020

41. ICAO, Unmanned Aircraft Systems (UAS) for Humanitarian Aid and Emergency Response Guidance U-AID, online: https:// www.icao.int/safety/UA/UAID/Documents/ICAO\%20UAID\%20Guidance\%20Material.pdf, accessed on 29/11/2020

42. ICAO, Unmanned Aircraft Systems Advisory Group (UAS-AG), online: https://www.icao.int/safety/UA/Pages/Unmanned-AircraftSystems-Advisory-Group-(UAS-AG).aspx, accessed on 29/11/ 2020

43. ICAO, Unmanned Aircraft Systems Traffic Management (UTM) A Common Framework with Core Principles for Global Harmonization, online: https:/www.icao.int/safety/UA/ Documents/UTM\%20Framework\%20Edition\%203.pdf, accessed on $29 / 11 / 2020$

44. EASA, "High-Level Meeting: Cybersecurity in Civil Aviation", 2016

45. EUR-Lex, Regulation (EU) 2018/1139 of the European Parliament and of the Council of 4 July 2018 on common rules in the field of civil aviation and establishing a European Union Aviation Safety Agency, and amending Regulations (EC) No 2111/2005, (EC) No 1008/2008, (EU) No 996/2010, (EU) No 376/2014 and Directives 2014/30/EU and 2014/53/EU of the European Parliament and of the Council, and repealing Regulations (EC) No 552/2004 and (EC) No 216/2008 of the European Parliament and of the Council and Council Regulation (EEC) No 3922/91

46. EASA, The European Plan for Aviation Safety (EPAS) 2018-2022, 2017, online: https://www.easa.europa.eu/sites/ default/files/dfu/EASA\%20MB\%20Decision\%2008 2017\%20Annex\%201\%20EPAS\%202018-2022.pdf, accessed on $29 / 11 / 2020$
47. J. Anton, "Cybersecurity; an EASA perspective on developments and challenges", online: https://www.iata.org/whatwedo/ workgroups/Documents/Paperless_Conference_2017/Day1/11001130_Cybersecurity_EASA.pdf, accessed on 29/11/2020

48. J. Rasmussen, EASA, "Conclusions of High Level Cybersecurity Conference", 2020, online: https://www.easa.europa.eu/newsroomand-events/events/2020-high-level-cybersecurity-conference, accessed on 29/11/2020

49. Commission Delegated Regulation (EU) 2019/945 of 12 March 2019 on unmanned aircraft systems and on third-country operators of unmanned aircraft systems, online: https://eurlex.europa.eu/legal-content/EN/TXT/PDF/?uri=CELEX: 32019R0945\&from $=E N$, accessed on 29/11/2020

50. Commission Delegated Regulation (EU) 2020/1058 of 27 April 2020 amending Delegated Regulation (EU) 2019/945 as regards the introduction of two new unmanned aircraft systems classes, online: https://eur-lex.europa.eu/legal-content/EN/TXT/ ?uri=CELEX\%3A32020R1058, accessed on 29/11/2020

51. Commission Implementing Regulation (EU) 2019/947 of 24 May 2019 on the rules and procedures for the operation of unmanned aircraft, https://eur-lex.europa.eu/eli/reg_impl/2019/947/ oj, accessed on $29 / 11 / 2020$

52. Act of 3 July 2002 - Aviation Law, Journal of Laws from 2002, No. 130, item 1112, online: http://isap.sejm.gov.pl/isap.nsf/ DocDetails.xsp?id=WDU20021301112, accessed on 29/11/2020

53. Act of 5 July 2018 on the National Cybersecurity System, Journal of Laws from 2018, item 1560, online: http:// www.dziennikustaw.gov.p1/D2018000156001.pdf, accessed on: 29/11/2020

Publisher's Note Springer Nature remains neutral with regard to jurisdictional claims in published maps and institutional affiliations.

Tomasz Balcerzak Adjunct at Lazarski University-Faculty of Law and Administration, Expert European Commission-Research Executive Agency (REA), Advisor-Malta Council for Science and Technology, Expert of European Global Navigation Satellite Systems Agency, previously Adjunct at Silesian University of Technology-Aviation Faculty, graduated Air Force Academy, received pilot, engineer degree, magistry studies and $\mathrm{PhD}$ at Warsaw University, MBA at Warsaw School of Economics. Autor or coauthor of more than 50 publications in transportation, logistics, aviation and space.

Mariusz Pyzynski is a specialist in aviation cybersecurity, focusing on the legal aspects. He received his master's degree in law at Lazarski University in Warsaw, Poland. He also obtained a postgraduate certificate in Air Law and Safety Management System (SMS) in Aviation at Lazarski University. Mr. Pyzynski is a Ph.D. candidate at the Institute of Air and Space Law, Faculty of Law and Administration at Lazarski University. He is also Assistant Aviation Cyber Security at the International Air Transport Association (IATA). Mr. Pyzynski is also a member of multiple international working groups on aviation cybersecurity. 